\title{
INTEGRAÇÃO DE MÉTODOS POTENCIAIS (GRAVIMETRIA E MAGNETOMETRIA) NA CARACTERIZAÇÃO DO EMBASAMENTO DA REGIÃO SUDOESTE DA BACIA DE PELOTAS, SUL DO BRASIL
}

\author{
Maria Luiza Correa da Camara Rosa ${ }^{1,2}$, Luiz José Tomazelli ${ }^{2,3}$, \\ Antonio Flávio Uberti Costa ${ }^{4}$ e Eduardo Guimarães Barboza ${ }^{2,5}$ \\ Recebido em 26 novembro, 2008 / Aceito em 5 janeiro, 2010 \\ Received on November 26, 2008 / Accepted on January 5, 2010
}

\begin{abstract}
Through the integrated application of gravity and magnetic methods, it was intended to contribute to structural and compositional characterization of Pelotas Basin basement. The study area is the south region of Rio Grande do Sul Coastal Province, located between latitudes $31^{\circ} 45^{\prime}$ and $34^{\circ} \mathrm{S}$ and longitudes $52^{\circ}$ and $53^{\circ} 30^{\prime}$ W. The interpretation of potential methods maps into a Geographic Information System (GIS) allowed verifying a complex structuration and a compositional heterogeneity of the bedrock. These structures are related to the Uruguaio-Sul-Rio-Grandense Shield evolution and with South Atlantic Ocean opening. A negative gravity anomaly in Banhado do Taim area was interpreted as a topographic low in the basin basement. In this region, previous works identified a segmentation in the Pleistocene depositional systems of the Rio Grande do Sul Coastal Plain. The presence of a basement low in the same position of the identified segmentation indicates that the stratigraphic record of the region was controlled by the basin basement. Therefore a control of geologic inheritance in the area is suggested, probable related to fault reactivation and differential subsidence associated with the bedrock compositional heterogeneity. Future studies with data acquisition in not covered areas (lagoons and swamps) and their integration with other methods could be able to improve and to test the present interpretations.
\end{abstract}

Keywords: geologic inheritance, gravity method, magnetic method, Rio Grande do Sul Coastal Plain.

RESUMO. Por meio da aplicação integrada dos métodos potenciais de gravimetria e magnetometria, visou-se contribuir com a caracterização do arcabouço estrutural e composicional do embasamento da Bacia de Pelotas. A área selecionada para este estudo é a região sul da Província Costeira do Rio Grande do Sul, entre as latitudes $31^{\circ} 45^{\prime}$ e $34^{\circ} \mathrm{S}$ e as Iongitudes $52^{\circ}$ e $53^{\circ} 30^{\prime} \mathrm{W}$. A interpretação integrada dos mapas gerados através dos métodos potenciais, em um Sistema de Informações Geográficas (SIG), permitiu verificar uma complexa estruturação e a heterogeneidade composicional do embasamento. Essa estruturação está relacionada com a evolução do Escudo Uruguaio-Sul-Rio-Grandense e com a abertura do Oceano Atlântico Sul. Uma anomalia gravimétrica negativa, na região do Banhado do Taim, foi interpretada como uma calha no embasamento. Nessa região, trabalhos anteriores identificaram uma segmentação nos sistemas deposicionais pleistocênicos da Planície Costeira do Rio Grande do Sul. A presença desta calha na mesma posição da segmentação identificada indica que o registro estratigráfico da região foi condicionado pelo embasamento, sugerindo a existência de um controle da herança geológica na área. Esse controle é possivelmente relacionado com a reativação de falhas e com a subsidência diferencial devido à heterogeneidade das litologias presentes no embasamento. Estudos futuros com a aquisição de novos dados em regiões onde não foram realizadas medidas (lagoas e banhados) e a integração com outros métodos possibilitarão melhorar e testar as interpretações realizadas.

Palavras-chave: herança geológica, gravimetria, magnetometria, Planície Costeira do Rio Grande do Sul.

\footnotetext{
1 Programa de Pós Graduação em Geociências, Instituto de Geociências, Universidade Federal do Rio Grande do Sul, Av. Bento Gonçalves, 9.500, 91501-970 Porto Alegre, RS, Brasil. Tel./Fax: (51) 3308-6340 - E-mail: luiza.camara@ufrgs.br

${ }^{2}$ Centro de Estudos de Geologia Costeira e Oceânica (CECO), Instituto de Geociências, Universidade Federal do Rio Grande do Sul, Av. Bento Gonçalves, 9.500, 91501970 Porto Alegre, RS, Brasil. Tel./Fax: (51) 3308-7160

${ }^{3}$ Departamento de Mineralogia e Petrologia, Instituto de Geociências, Universidade Federal do Rio Grande do Sul, Av. Bento Gonçalves, 9.500, 91501-970 Porto Alegre, RS, Brasil. Tel./Fax: (51) 3308-6381 - E-mail: luiz.tomazelli@ufrgs.br

${ }^{4}$ Departamento de Geologia, Instituto de Geociências, Universidade Federal do Rio Grande do Sul, Av. Bento Gonçalves, 9.500, 91501-970 Porto Alegre, RS, Brasil. Tel./Fax: (51) 3308-6337 -E-mail: antonio.afc@terra.com.br

${ }^{5}$ Departamento de Paleontologia e Estratigrafia, Instituto de Geociências, Universidade Federal do Rio Grande do Sul, Av. Bento Gonçalves, 9.500, 91501-970 Porto Alegre, RS, Brasil. Tel./Fax: (51) 3308-7160 - E-mail: eduardo.barboza@ufrgs.br
} 


\section{INTRODUÇÃo}

0 reconhecimento de feições estruturais que possam controlar 0 preenchimento de uma bacia sedimentar possui grande importância na compreensão de sua história evolutiva. 0 entendimento da compartimentação estrutural pode servir de guia para definir as principais zonas de transferência de sedimentos, desde 0 embasamento até suas porções mais profundas.

A Planície Costeira do Rio Grande do Sul (PCRS) representa a seção superior emersa da Bacia de Pelotas, correspondente a depósitos sedimentares formados desde o Plioceno até 0 Recente. A interpretação da gênese e da distribuição espacial dos sistemas deposicionais que afloram na PCRS baseia-se em fatores da dinâmica global e da dinâmica costeira. 0 principal fator relativo à dinâmica global, que tem sido considerado na evolução desses sistemas, é a variação glácio-eustática (Villwock \& Tomazelli, 1995). Uma variável pouco considerada é a herança geológica. A ocorrência de zonas de fraqueza localizadas ao longo de estruturas pré-existentes, bem como a morfologia do embasamento da bacia podem influenciar na disposição dos sistemas deposicionais que a constituem (Asmus \& Paim, 1986; Fonseca, 2006).

Através da aplicação integrada dos métodos potenciais de gravimetria e magnetometria, visou-se contribuir com a caracterização do arcabouço estrutural e composicional do embasamento da Bacia de Pelotas na área de estudo. A partir de tal caracterização, procurou-se investigar a influência da herança geológica nos sistemas deposicionais da PCRS. Dentre as possíveis influências, considera-se a existência de feições estruturais e/ou relacionadas ao paleorelevo do embasamento, que possam controlar o posicionamento dos sistemas deposicionais da PCRS.

A área de estudo localiza-se na região sul da Província Costeira do Rio Grande do Sul, aproximadamente entre as latitudes $31^{\circ} 45^{\prime}$ e $34^{\circ} \mathrm{S}$ e as longitudes $52^{\circ}$ e $53^{\circ} 30^{\prime} \mathrm{W}$ (Fig. 1).

\section{CONTEXTO GEOLÓGICO}

A área de estudo encontra-se no contexto geológico da Província Costeira do Rio Grande do Sul. Definida por Villwock (1984), essa província abrange os depósitos sedimentares da Bacia de Pelotas, ou Terras Baixas e o embasamento adjacente, ou Terras Altas. 0 embasamento da área de estudo aflora na região oeste e é constituído por rochas do Escudo Uruguaio-Sul-Rio-Grandense, pertencente à Província Mantiqueira (Almeida et al., 1981), e por rochas da Bacia do Paraná (Fig. 1).

As rochas pertencentes ao Escudo Sul-Rio-Grandense foram geradas no Ciclo Brasiliano (Neoproterozóico a Eopaleozóico) e compõem a unidade denominada Cinturão Dom Feliciano
(Fragoso-César et al., 1982; Chemale Jr et al., 1995), Arco Magmático I (Fernandes et al., 1995) ou Batólito de Pelotas (Fragoso-César et al., 1986; Philipp, 1998; Philipp \& Machado, 2001 e Philipp et al., 2003). Essa unidade corresponde a uma faixa móvel alongada segundo a direção NE-SW com idades entre 850 e 500 Ma (Soliani Jr, 1986; Chemale Jr et al., 1995; Babinski et al., 1997).

A Bacia do Paraná corresponde a uma bacia intracontinental que se desenvolveu entre o Neo-Ordoviciano e o Neocretáceo (Milani, 2000). No Rio Grande do Sul, seus depósitos encontramse sobre o Escudo Sul-Rio-Grandense e a Bacia do Camaquã. Nas adjacências da área deste estudo afloram rochas sedimentares e magmáticas relacionadas à Bacia do Paraná. Na região do Município de Jaguarão (RS) são encontradas rochas da Formação Serra Geral (Fácies Jaguarão), correspondentes a dacitos e riodacitos (Vieira Jr \& Roisenberg, 1985 apud Costa \& Ramgrab, 1989). Através de datações realizadas pelo método K/Ar (143 \pm 10 Ma e $157 \pm 4 \mathrm{Ma}$ ), Vieira Jr \& Roisenberg (1985) associaram estas manifestações com a abertura do Oceano Atlântico Sul. Em território uruguaio, as unidades vulcânicas que afloram nas adjacências da área de estudo são denominadas como formações Mariscala e Arequita (Bossi et al., 1998; Bossi \& Ferrando, 2001). Bossi \& Umpierre (1975) estimam que um volume em torno de 20.000 km³ de rochas vulcânicas, além de múltiplas intrusões na forma de diques e sil/s, tenham sido gerados no magmatismo mesozóico relacionado à abertura do 0ceano Atlântico Sul.

A Bacia de Pelotas é uma bacia marginal preenchida por seqüências clásticas continentais, transicionais e marinhas (Asmus \& Porto, 1972). Sua história teve início no Cretáceo, a partir dos movimentos tectônicos que culminaram com a abertura do Oceano Atlântico Sul. Essa bacia limita-se ao norte com a Bacia de Santos, através do alto estrutural representado pela Plataforma de Florianópolis e pelo Alto de São Paulo (Gamboa \& Rabinowitz, 1981). Ao sul, a Bacia de Pelotas limita-se com a Bacia de Punta del Este pelo Alto do Cabo Polônio, em território uruguaio (Urien \& Martins, 1978).

A PCRS é uma feição fisiográfica que corresponde à seção superior emersa da Bacia de Pelotas. Nela estão expostos sedimentos de quatro sistemas deposicionais do tipo Laguna-Barreira que se desenvolveram em resposta aos ciclos transgressivosregressivos controlados pela glácio-eustasia (Villwock et al., 1986). As idades desses sistemas (400, 325, 125 e 7 ka ao recente) foram estabelecidas a partir da correlação com os estágios isotópicos do oxigênio (picos 11, 9, 5 e 1, respectivamente) das curvas de Shackleton \& Opdyke (1973) e Imbrie et al. (1984). Em sua porção oeste, junto ao embasamento, ocorrem depósitos 


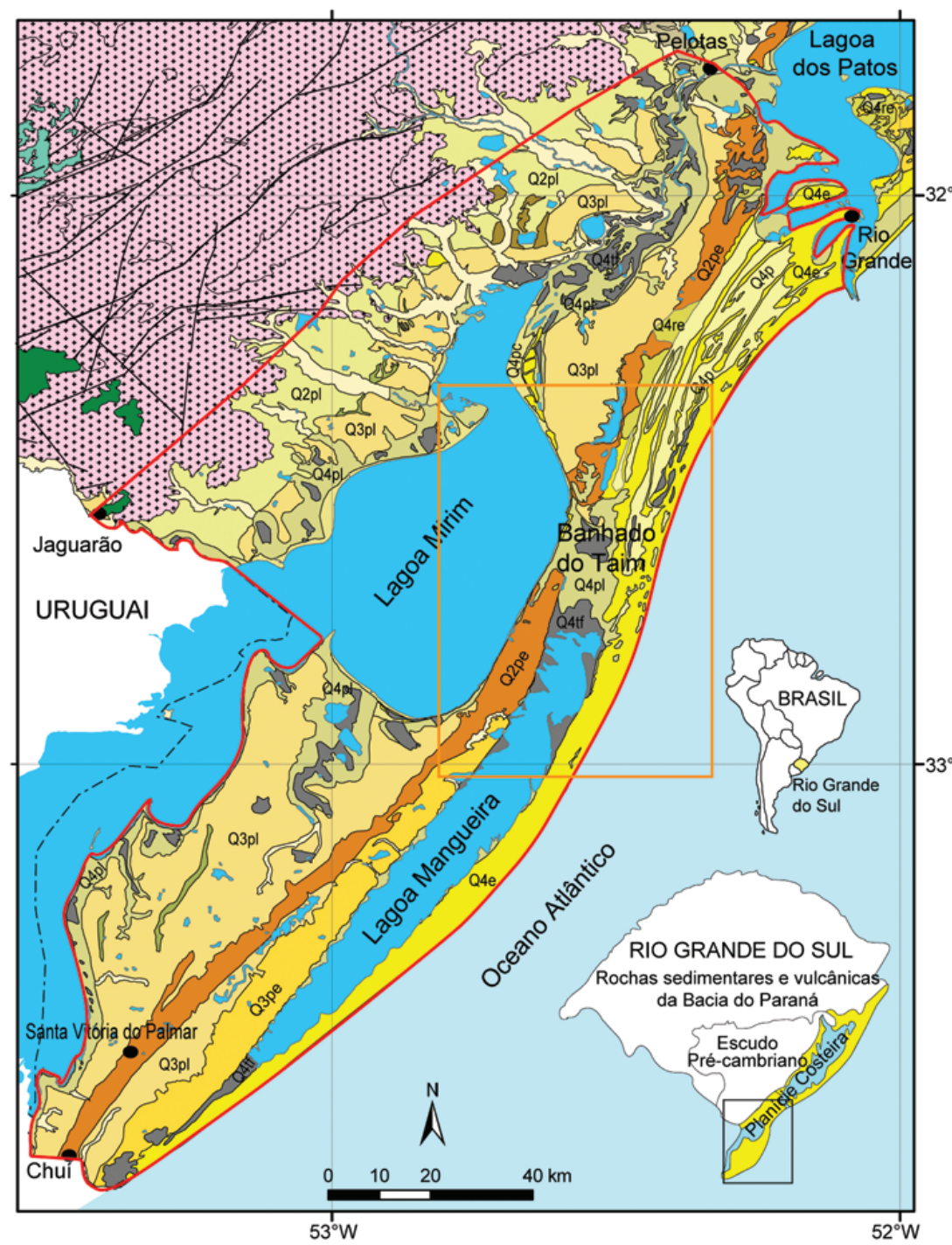

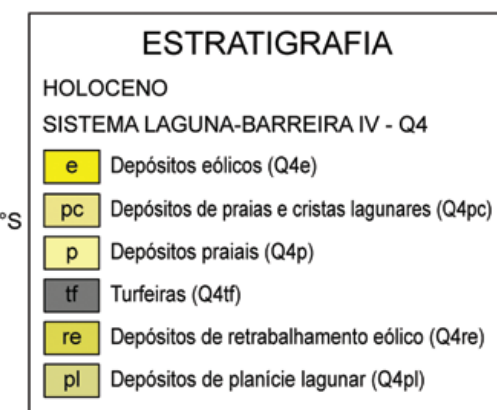

PLEISTOCENO

SISTEMA LAGUNA-BARREIRA III - Q3

pe Depósitos praiais e eólicos (Q3pe)

$\mathrm{pl}$ Depósitos de planície lagunar (Q3pl)

SISTEMA LAGUNA-BARREIRA II - Q2

pe Depósitos praiais e eólicos (Q2pe)

$\mathrm{pl}$ Depósitos de planície lagunar (Q2pl)

PLIOCENO AO RECENTE

SISTEMA DE LEQUES ALUVIAIS

NQca Depósitos coluvio-aluviais

EMBASAMENTO PRÉ-CENOZÓICO

Bacia do Paraná (Paleozóico/Mesozóico)

Grupo Săo Bento - Fm. Serra Geral (Fácies Jaguarão)

Grupo Guatá - Fm. Rio Bonito

Escudo Pré-Cambriano

Província Mantiqueira - Escudo Sul-Rio-Grandense

$\begin{array}{ll}\square & \text { Área de estudo } \square \text { Área de } \\ \text { detalhe } \\ -\quad \text { Municípios } \\ --- \text { Limite internacional } \\ - \text { Contato geológico } \\ \square \text { Estruturas } \\ \text { Lagos, Lagoas }\end{array}$

Figura 1 - Mapa geológico com a localização da área de estudo e da área de detalhe (modificado de CPRM, 2008).

sedimentares que compõem um sistema de leques aluviais o qual se desenvolveu desde o Plioceno até o Recente (Villwock, 1984).

\section{MATERIAIS E MÉTODOS}

Para melhor definir 0 arcabouço estrutural e as litologias presentes no embasamento da Bacia de Pelotas, na área de estudo, foram aplicados os métodos potenciais de gravimetria e magnetometria. Como apoio foi utilizado um sistema de posicionamento global diferencial (DGPS) que propicia a obtenção de coordenadas com precisão decimétrica. Os equipamentos utilizados pertencem ao Departamento de Geodésia (gravímetro Scintrex modelo CG3), ao Departamento de Geologia (magnetômetro Scintrex modelo ENVIMAG) e ao Centro de Estudos de Geologia Costeira e Oceânica
(DGPS - Trimble modelo Pro-XRS) do Instituto de Geociências da Universidade Federal do Rio Grande do Sul.

Os dados foram adquiridos a partir de levantamentos junto às estradas e acessos presentes na região, em seções correspondentes a perfis paralelos e transversais ao eixo da bacia (NE-SW e NW-SE). A aquisição foi realizada em dois níveis de detalhe. 0 primeiro, com objetivo regional, contou com perfis cujas estações foram medidas a cada $5 \mathrm{~km}$. 0 segundo, de maior detalhe, contou com estações a cada $1 \mathrm{~km}$.

A área escolhida para esse detalhe localiza-se junto ao Banhado do Taim, onde foi identificada, em trabalhos anteriores, uma segmentação nas barreiras pleistocênicas (Villwock \& Tomazelli, 1995; Ayup-Zouain et al., 2003; Rosa et al., 2007). Essa segmentação é atribuída à ocorrência de vales incisos du- 
rante períodos de queda do nível do mar (Tomazelli et al., 2008). A análise dessa área teve 0 objetivo de verificar se 0 posicionamento da segmentação nas barreiras pleistocênicas está sujeito a algum controle exercido pela configuração do embasamento.

Foram adquiridas 681 estações de gravimetria e 641 estações de magnetometria. Dessas, 308 estações com ambas as medidas encontram-se na área de detalhe. Foram utilizadas 60 estações do levantamento gravimétrico previamente realizado e utilizado por Costa (1997) em sua Tese de Doutorado. Essas estações, localizadas junto às estradas BR-116 e BR-392, estão identificadas no mapa de pontos (Fig. 2).

Os valores da anomalia Bouguer foram obtidos após serem efetuadas as correções de deriva do instrumento, latitude, altitude, marés e Bouguer. Tais correções foram efetuadas no programa Anomalia, gentilmente cedido pelo Prof. Dr. Sergio Florencio de Souza do Departamento de Geodésia do Instituto de Geociências da Universidade Federal do Rio Grande do Sul. As estações utilizadas para corrigir a deriva do instrumento localizam-se na Prefeitura Municipal de Pelotas, Estação 141583 (Observatório Nacional), coordenadas $31^{\circ} 45^{\prime} 36^{\prime \prime} \mathrm{S}, 52^{\circ} 20^{\prime} 24^{\prime \prime} \mathrm{W}$ e $10,99 \mathrm{~m}$ de altitude, com $\mathrm{G}=979466,630 \mathrm{mGal}$ e incerteza de 0,013 mGal e na antiga subprefeitura do Município do Chuí, Estação 141883 (Observatório Nacional), coordenadas $33^{\circ} 41^{\prime} 24^{\prime \prime}$ S, 53⒉ $27^{\prime} 00^{\prime \prime} \mathrm{W}$ e 13,39 m de altitude, com $\mathrm{G}=979655,780 \mathrm{mGal}$ e incerteza de 0,016 mGal. A correção do terreno não foi efetuada, porém considerando que a área de estudo é extremamente plana, a influência do relevo é minimizada.

Devido à dimensão da área de estudo e ao objetivo da identificação de anomalias com amplitudes superiores a variação normal, optou-se por não realizar um monitoramento minucioso da variação diurna do campo magnético. Para possibilitar a correlação dos dados adquiridos em períodos diferentes e para avaliar a confiabilidade dos mesmos foram criadas duas bases de apoio. Nestas bases foram realizadas medidas sistemáticas, em um procedimento similar ao do levantamento gravimétrico, iniciando e finalizando cada dia de campo com a leitura em uma dessas estações.

A estação principal (EP) localiza-se junto a um acesso para 0 Município de Pelotas, na BR-392, coordenadas $31^{\circ} 45^{\prime} 13^{\prime \prime} S$, $52^{\circ} 24^{\prime} 05^{\prime \prime} \mathrm{W}$ e $3,71 \mathrm{~m}$ de altitude. A segunda estação localiza-se na BR-471, no acesso ao Município do Chuí, e foi criada devido à distância e a impossibilidade de retornar a EP em alguns dias do levantamento. Essa estação teve seu valor definido após ter sido medida em um dia cujo início e fim do levantamento foi realizado na EP. Os dados foram normalizados com base em um vaIor médio obtido na EP. Constatou-se que a variação diurna não ultrapassou os $30 \mathrm{nT}$ em um único dia, e chegou a até $60 \mathrm{nT}$ ao longo de todo o levantamento. Como as anomalias identificadas possuem valores maiores que tal variação, essas se comportarão como um ruído (background), o que foi considerado nas interpretações realizadas.

Após as correções, os dados de gravimetria e magnetometria foram importados para o programa Oasis Montaj ${ }^{\circledR}$. Nesse programa, foram gerados os mapas da anomalia Bouguer e do campo magnético total através da técnica de interpolação da mínima curvatura nas duas escalas distintas. Na geração dos mapas de escala regional a resolução espacial do grid obtido foi de $1.680 \mathrm{~m}$ enquanto nos mapas da área de detalhe foi de $880 \mathrm{~m}$ (Figs. 3 e 4).

Posteriormente, empregou-se a filtragem do campo regional para obtenção das anomalias residuais. Para a gravimetria, foi utilizada a filtragem espectral, através da remoção dos maiores comprimentos de onda. Os dados foram convertidos para 0 domínio da freqüência através da transformada rápida de Fourier (Fourier Fast Transform - FFT). Utilizando o filtro gaussiano, foram removidas as anomalias com comprimento de onda acima de $40.000 \mathrm{~m}$, obtendo-se como resultado o mapa residual (Figs. 5 e 6 ). 0 comprimento de $40.000 \mathrm{~m}$ foi selecionado por representar o dobro da máxima separação entre as estações, o que ocorre na região das lagoas (Freqüência de Nyquist). Testes realizados com comprimentos menores geraram mapas muito ruidosos, tanto na área de estudo completa quanto na área de detalhe, o que é atribuído aos vazios na malha do levantamento. A irregularidade na distribuição dos perfis dos levantamentos deve-se a existência de regiões inacessíveis, como banhados e lagoas e a impossibilidade da realização de aquisições por meios não terrestres (Fig. 2).

Para a magnetometria, o mapa com as anomalias residuais foi obtido através da subtração do IGRF (International Geomagnetic Reference Field) e posterior filtragem espectral, de forma idêntica (mesmo comprimento de onda) à realizada na gravimetria (Figs. 5 e 6 ).

As tentativas de obter mapas residuais com freqüências mais altas, através de outros filtros (polinomiais, derivadas, entre outros) também resultaram em mapas muito ruidosos. Esse problema é atribuído a malha de amostragem e, portanto para não originar anomalias inexistentes, optou-se por não gerar outros mapas.

Os mapas obtidos foram integrados e interpretados junto a outras informações em um Sistema de Informações Geográficas (SIG), utilizando-se para tanto o programa $\operatorname{ArcGIS}{ }^{\circledR}$. Essas informações incluíram: imagens de satélite, modelo digital de 


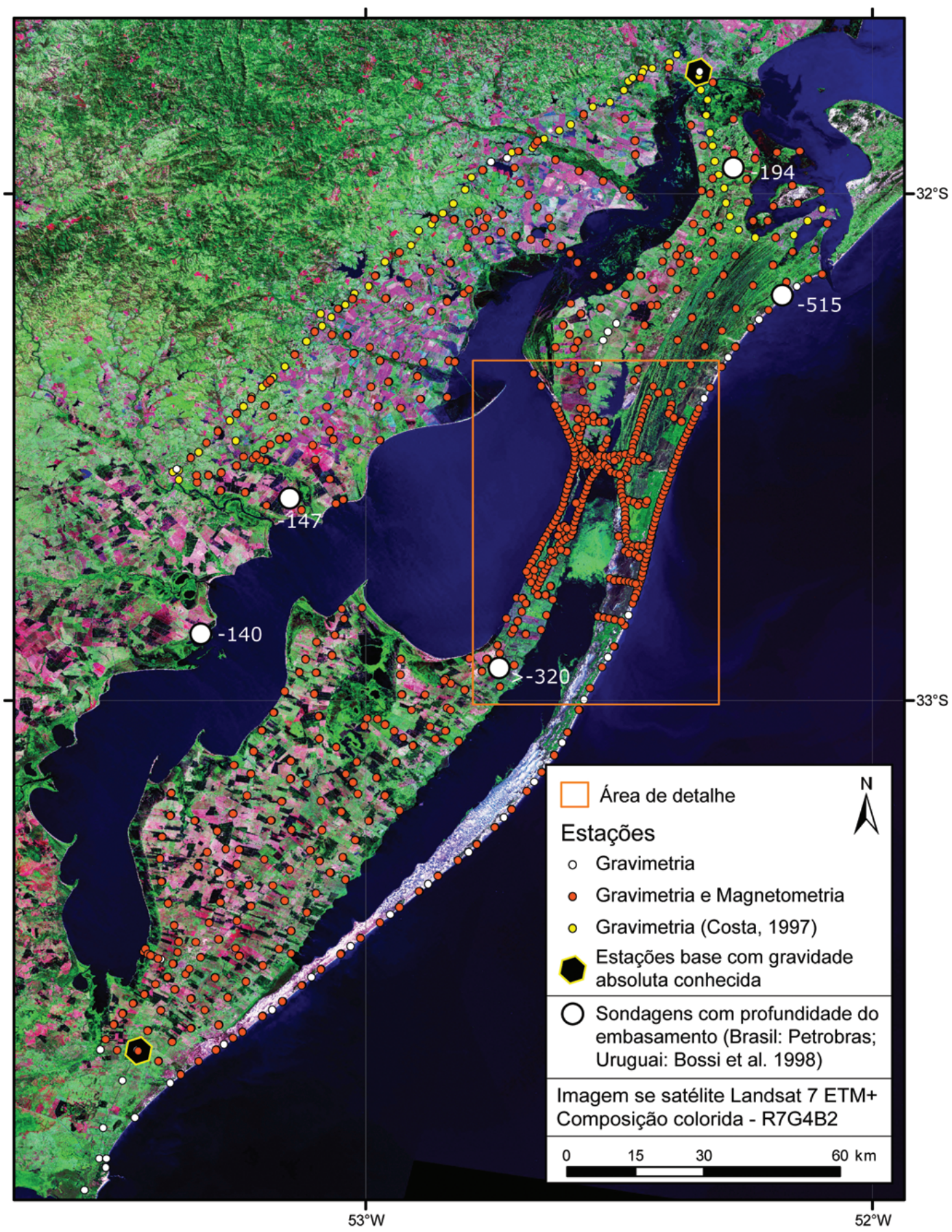

Figura 2 - Mapa com a localização das estações gravimétricas e magnetométricas adquiridas neste estudo e integradas do trabalho de Costa (1997). Destaca-se a localização e profundidade do embasamento obtida por sondagens perfuradas pela Petrobras (no Brasil) e por estudos realizados no Uruguai (Bossi et al., 1998).

elevação do terreno, mapas geológicos, base cartográfica e dados de levantamentos com DGPS (pré-existentes e adquiridos neste estudo). Outro dado integrado ao SIG foram sondagens perfuradas pela Petrobras no Brasil, e por estudos desenvolvidos no Uruguai (Fig. 2). As profundidades e a composição do embasamento obtidas por estas sondagens foram extremamente importantes nas interpretações realizadas.

Na área de detalhe foi selecionado um perfil para a realização de uma modelagem quantitativa dos dados. Esse perfil foi obtido junto aos mapas residuais no programa Oasis Montaj ${ }^{\circledR}$. 

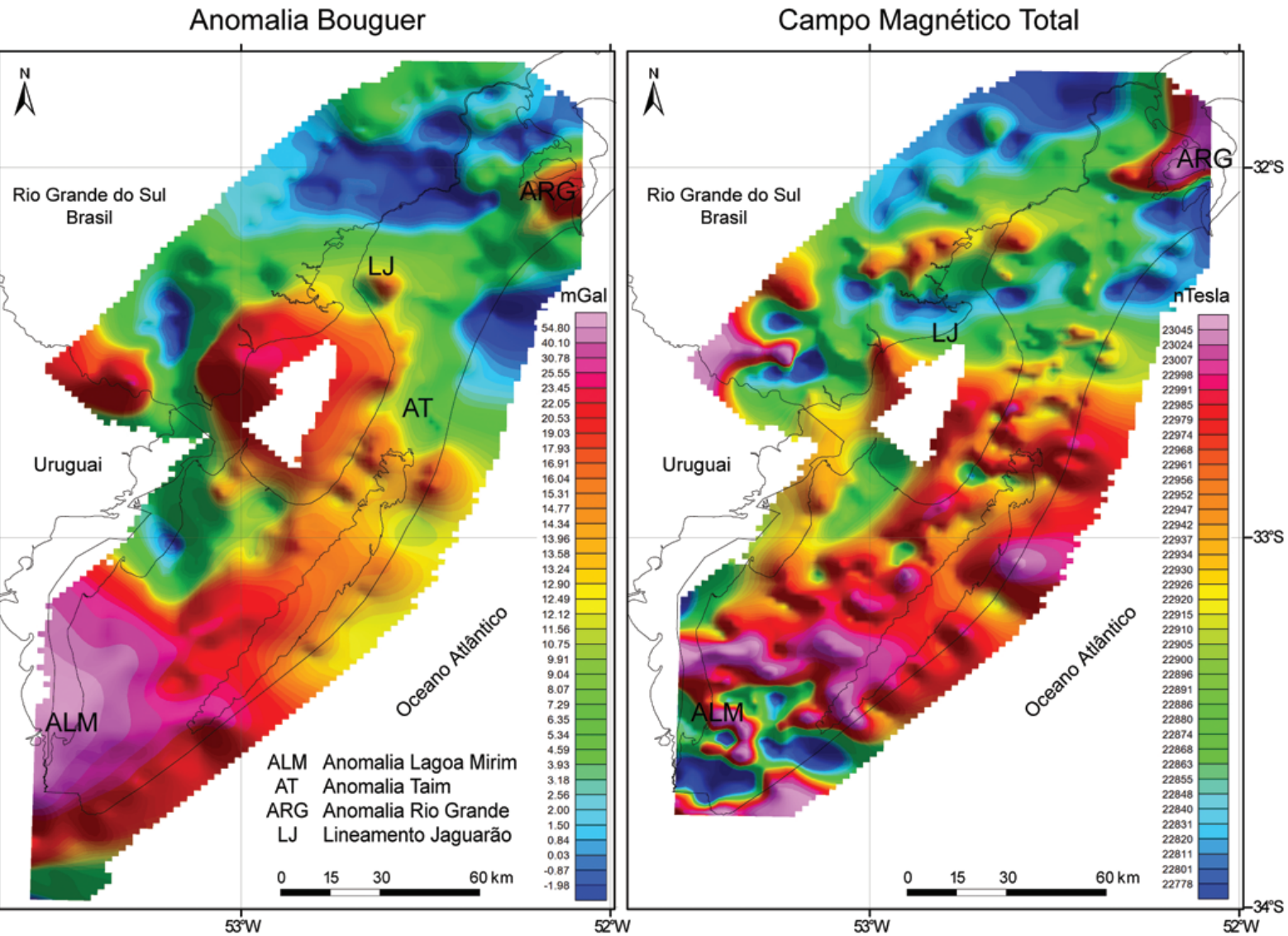

Figura 3 - Mapas da anomalia Bouguer e do campo magnético total para a escala de análise regional com o posicionamento das principais anomalias identificadas.

Os valores das coordenadas e da anomalia em cada ponto do perfil foram exportados na forma de uma tabela ASCII. A modelagem foi realizada nos programas Grav2dc e Mag2dc, desenvolvidos por G.R.J. Cooper, da Escola de Geociências da Universidade de Witwatersrand. Esses programas são disponibilizados gratuitamente e podem ser obtidos na internet (http://web.wits.ac.za/Academic/Science/GeoSciences/ Research/Geophysics/GordonCooper/Software.htm).

Através da geração e manipulação interativa de corpos 2.5D, a curva calculada pelo programa é ajustada à curva do perfil. Os corpos são definidos por parâmetros como a susceptibilidade magnética (em uSI ou c.g.s) para a modelagem magnética e 0 contraste de densidade para a modelagem gravimétrica, além de suas dimensões e profundidades. Para o cálculo da anomalia, os programas utilizam os métodos de Talwani et al. (1959). Para a inversão do modelo, são selecionados os parâmetros a serem modificados dentro de limites definidos, obtendo-se como resultado um melhor ajuste das curvas.

Na modelagem realizada, os corpos foram inicialmente definidos com base no ajuste das curvas da anomalia magnética resi- dual, no programa Mag2dc. Esses corpos foram importados para o programa Grav2dc, onde a curva da anomalia Bouguer residual calculada foi ajustada à curva observada. Esse ajuste foi obtido através de variações na espessura de um corpo representativo dos sedimentos da Bacia de Pelotas.

\section{RESULTADOS E DISCUSSÕES}

A análise dos resultados obtidos levou em conta a distribuição dos pontos do levantamento, que devido a restrições de acesso, é irregular em algumas áreas. Os resultados são apresentados de acordo com os níveis de detalhamento, divididos em Escala Regional e Escala de Detalhe.

\section{Escala Regional}

No mapa da anomalia Bouguer (Fig. 3), observam-se valores mais elevados na região sul e uma tendência de queda para norte 0 que reflete 0 campo gravimétrico regional da área de estudo. No mapa residual, esta tendência é eliminada, verificandose um relevo gravimétrico mais heterogêneo (Fig. 5). Na porção 

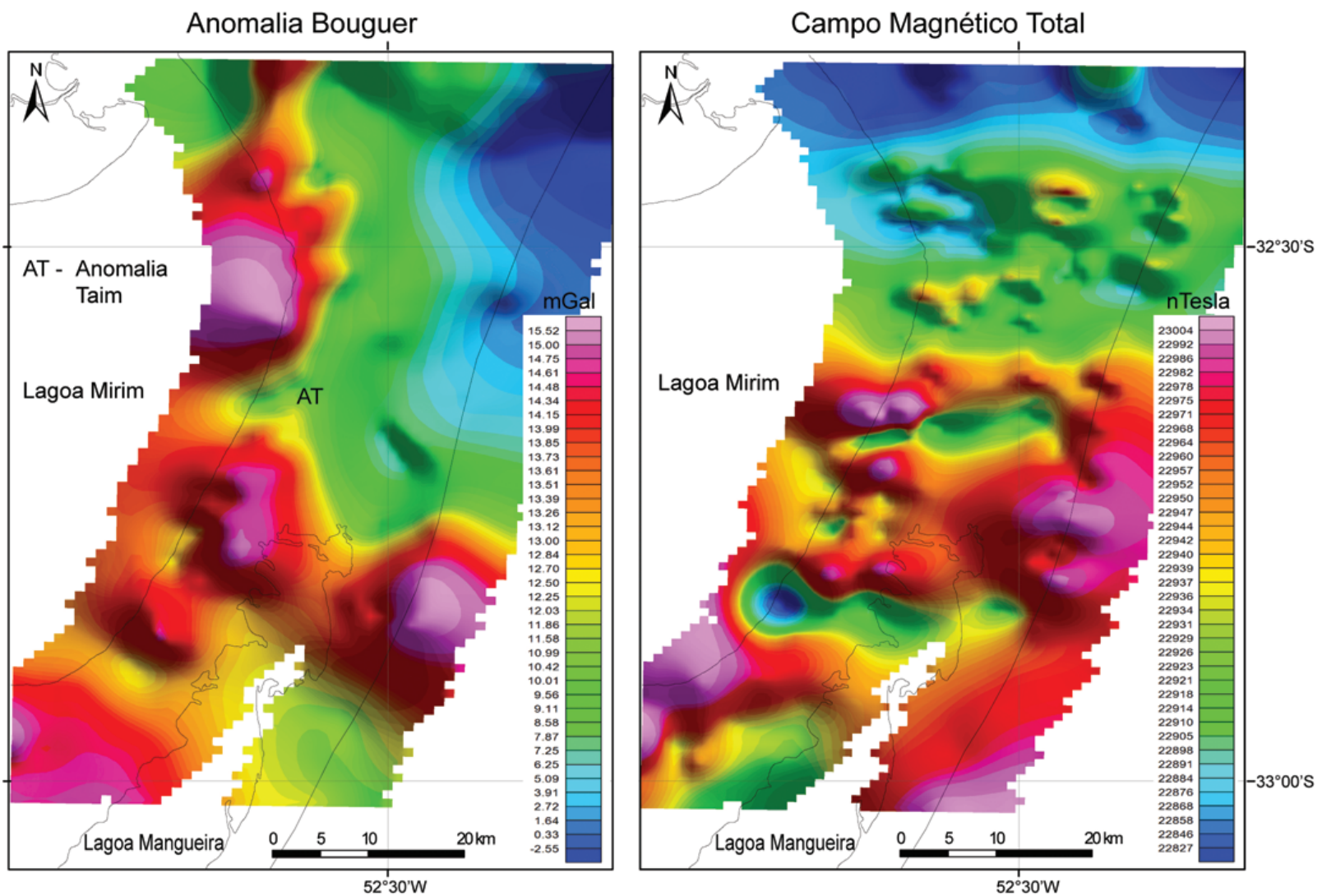

Figura 4 - Mapas da anomalia Bouguer e do campo magnético total para a escala de detalhe, junto à região do Banhado do Taim.

sul da área, destaca-se uma expressiva anomalia positiva, com ramificações para NE. Anomalias menores com orientação NWSE e E-W estão presentes na porção central. Além de anomalias menores, uma grande anomalia positiva com direção aproximadamente E-W que muda para NW, ocorre no setor norte.

$\mathrm{Na}$ área de estudo, as anomalias magnéticas são definidas pelo eixo entre um alto a norte e um baixo a sul. No mapa do campo magnético total podem ser observados distintos padrões do relevo magnético (Fig. 3). Com a remoção do IGRF e posterior filtragem, observa-se a presença de diversas anomalias com orientação E-W e NW-SE na porção sul da área, onde 0 relevo magnético caracteriza-se por altos e baixos com até $260 \mathrm{nT}$ de amplitude. Na região central predominam anomalias com menores amplitudes (máximo de 140 nT) e, com exceção de duas anomalias NE-SW a norte do paralelo $33^{\circ} \mathrm{S}$, os eixos possuem direção E-W e NW-SE. No setor norte as anomalias são mais contínuas, destacando-se um eixo NE-SW no paralelo $32^{\circ} \mathrm{S}$ junto ao Município de Rio Grande (Fig. 5).

A comparação do mapa da anomalia Bouguer residual com o mapa da anomalia magnética residual permite a realização de diversas correlações. A anomalia positiva identificada na região sul, na fronteira com o Uruguai, foi reconhecida em trabalhos anteriores e denominada Anomalia Chuí (Hales, 1973) ou Anomalia Gravimétrica Lagoa Mirim (ALM - Reitmayr, 1989). Essa anomalia possui continuidade no Uruguai e foi modelada por Reitmayr (2001), que a atribuiu à presença de um corpo intrusivo de alta densidade, o qual foi coberto por rochas vulcânicas das formações Puerto Gómez, Arequita e Mariscala, e pelos sedimentos cenozóicos.

Algumas interpretações consideram que a ALM poderia estar associada a um processo de ascensão mantélica (Introcaso \& Huerta, 1982; Rossello et al., 2007). Reitmayr (2001) comparou a ALM com a anomalia de Trompsburg, na África do Sul, onde sondagens revelaram a presença de gabros e anortositos. Suspeitas da presença de chaminés kimberlíicas em Trompsburg motivam um interesse econômico sobre a ALM (Reitmayr, 2001).

0 relevo magnético heterogêneo, com anomalias de grande amplitude na área da ALM, indica a presença de rochas relacionadas às formações Puerto Gómez, Arequita e Mariscala, que ocorrem no Uruguai. Uma sondagem realizada na região (Puerto 

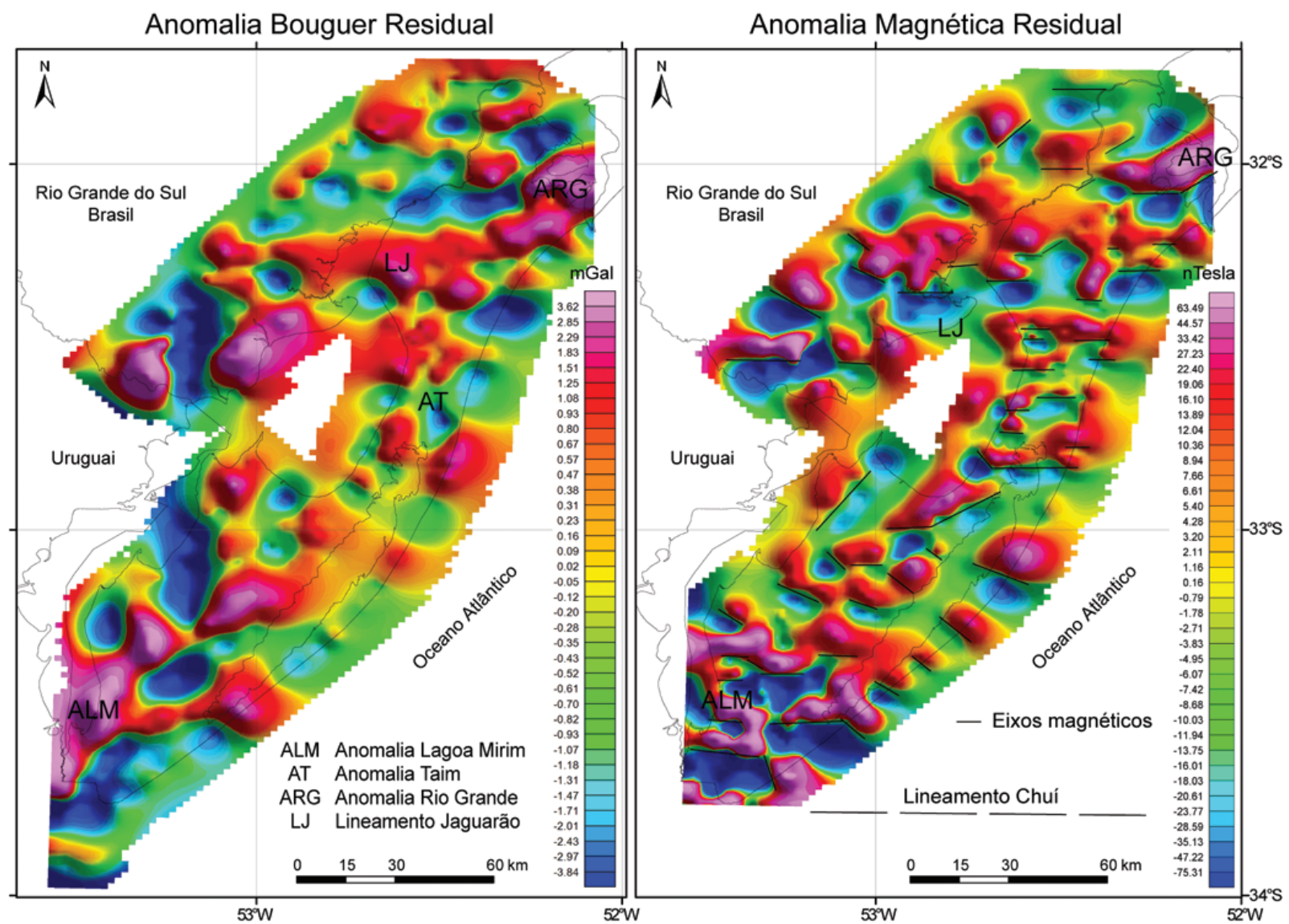

Figura 5 - Mapas residuais das anomalias Bouguer e magnética para a escala de análise regional, gerados a partir da remoção dos comprimentos de onda maiores que 40.000 m com o filtro gaussiano (após remoção do /GRF para o mapa da anomalia magnética).

Gómez, Uruguai - Caorsi \& Goñi, 1958 apud Bossi et al., 1998), revela uma espessura de quase $1.000 \mathrm{~m}$ de rochas vulcânicas, as quais iniciam a $220 \mathrm{~m}$ de profundidade e prosseguem até a base da sondagem, a uma profundidade de $1.200 \mathrm{~m}$. A análise geoquímica de testemunhos desta sondagem revela uma variação composicional (Gómez \& Masquelin, 1996). Abaixo de $650 \mathrm{~m}$ de profundidade, foram encontrados traquibasaltos do tipo MORB, característicos de um fundo oceânico. Datações pelo método Ar/Ar em rocha total indicam uma idade entre 127 e $137 \mathrm{Ma}$ (Turner et al., 1994). Acima dos $650 \mathrm{~m}$ há uma mudança nas características geoquímicas, cuja composição torna-se mais ácida e indica a transição para um ambiente tipicamente continental.

Veroslavsky et al. (2007) sugeriram que as vulcânicas encontradas poderiam representar uma proto dorsal oceânica. Rossello et al. $(1999,2007)$ propuseram que 0 lineamento formado pelas bacias Santa Lucia, localizada a norte de Montevidéu, e Mirim, junto à Lagoa Mirim, seria a expressão tectônica de um aulacógeno. Segundo os autores, o abandono do rifteamento devese a maior facilidade de abertura junto às estruturas pré-existentes no Cinturão Dom Feliciano. Desta forma, a ALM representaria um gráben gerado nos movimentos iniciais de abertura do Oceano Atlântico Sul. A grande espessura de rochas densas e magnéticas seria responsável pelas anomalias observadas.

Junto à Bacia da Lagoa Mirim são reconhecidos fenômenos de reativação tectônica durante o Cenozóico, que seguem padrões de deformação para a América do Sul (Cobbold et al., 1996 apud Rossello et al., 1999). A elevada densidade das litologias presentes na região poderia influenciar este fenômeno.

Na região central da área de estudo, anomalias magnéticas com direção NW-SE, correlacionam-se com anomalias gravimétricas positivas de mesma direção. Nas porções central e norte destacam-se eixos de anomalias magnéticas, com orientação E-W, que também se correlacionam a anomalias gravimétricas positivas.

Uma análise associando os padrões do campo magnético com estruturas presentes a aproximadamente $50 \mathrm{~km}$ a noroeste da área deste estudo, foi realizada por Costa \& Caldasso (1994). Nessa análise, foram definidos três padrões de alinhamentos 

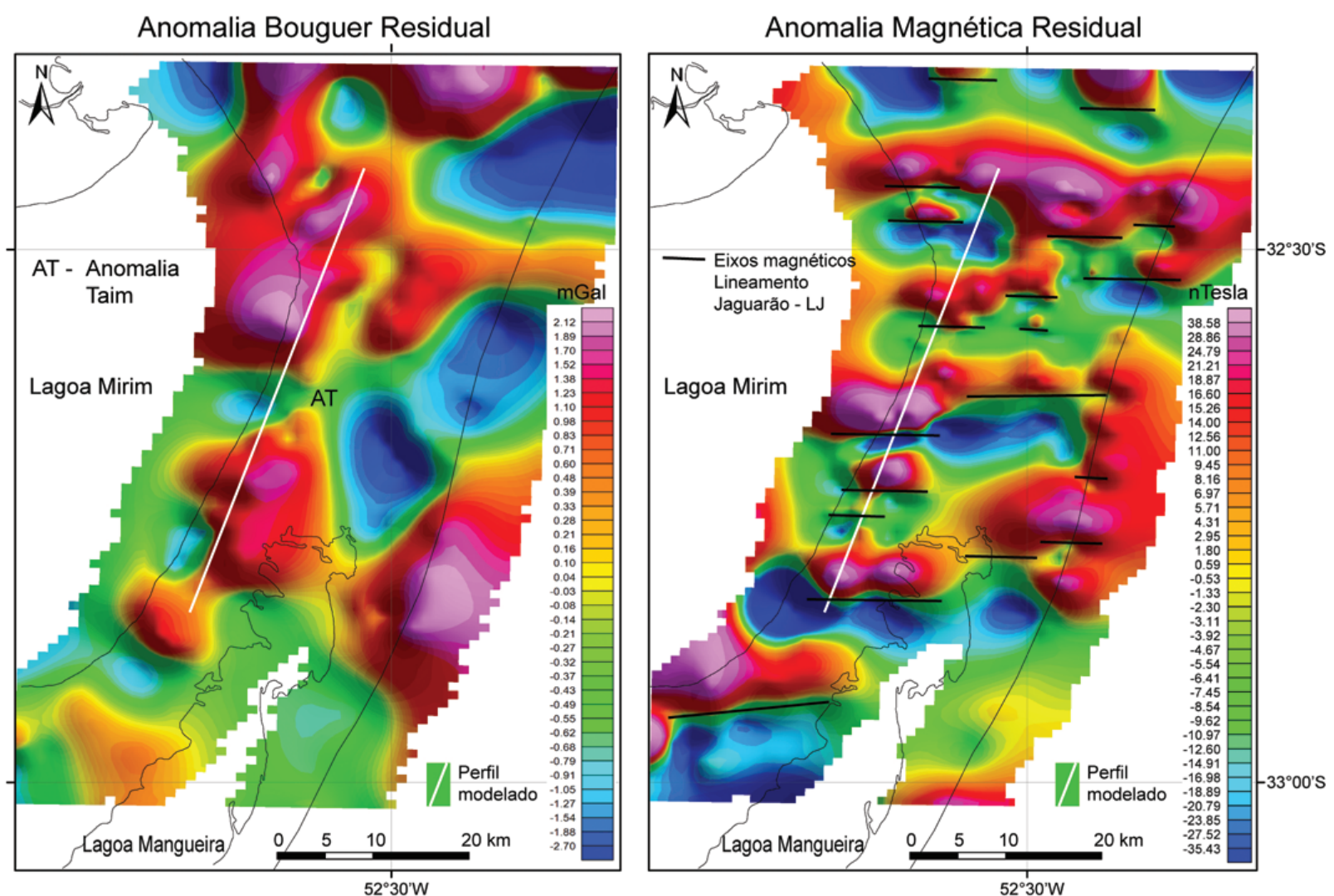

Figura 6 - Mapas residuais das anomalias Bouguer e magnética para a escala de detalhe junto à região do Banhado do Taim. De forma análoga à escala regional, esses mapas foram obtidos a partir da remoção dos comprimentos de onda maiores que $40.000 \mathrm{~m}$ com o filtro gaussiano (após remoção do /GRF para 0 mapa da anomalia magnética). Destaca-se a localização do perfil modelado, ilustrado na Figura 8.

magnéticos. 0 primeiro, devido à presença de rochas orientadas entre E-W e $\mathrm{N} 70^{\circ} \mathrm{E}$ com mergulhos de $30^{\circ}$ a $70^{\circ}$ para S/SE, corresponde à exposição de granitóides mais antigos, sendo identificada no terreno através de medidas em enclaves gnáissicos. Esse é o mesmo padrão predominantemente encontrado na área do presente estudo (Fig. 5).

0 segundo padrão possui orientação $N 30^{\circ}-50^{\circ} \mathrm{E}$, e corresponde a falhas dúcteis relacionadas à transcorrência brasiliana, as quais controlaram o posicionamento de granitos tardios. Um terceiro padrão, com alinhamentos orientados a WNW-ESSE foi relacionado com intrusões de diabásio. Esses alinhamentos também são observados, principalmente nos setores sul e central, da área deste estudo.

Na porção oeste da Lagoa Mirim, Costa \& Ramgrab (1989) já haviam identificado o primeiro padrão. Este ocorre na forma de uma série de eixos magnéticos com orientação E-W, interpretados como diques encaixados em um sistema de fraturas. Esse sistema representaria fraturas profundas implementadas e/ou reativadas no evento tectono-magmático de abertura do Atlântico
Sul, que deu origem à Bacia de Pelotas. Tais anomalias foram designadas como uma feição estrutural, denominada Lineamento Jaguarão (LJ). 0 LJ possui a mesma orientação do Lineamento Chuí (Zona de Fratura do Chuí - Alves, 1981), junto ao limite territorial do Brasil com o Uruguai, e de alinhamentos magnéticos identificados pela Prakla (1969) na porção submersa da Bacia de Pelotas.

Costa \& Ramgrab (1989) associaram o LJ com os derrames vulcânicos intermediários a ácidos, de idade mesozóica, que afloram próximo ao Município de Jaguarão descritos por Vieira Jr \& Roisenberg (1985). Estas feições também podem ser associadas com as unidades vulcânicas que afloram no Uruguai, a oeste e a sul da Lagoa Mirim. A continuidade destas anomalias para leste, na direção da plataforma continental e para oeste da Lagoa Mirim, no Uruguai, pode ser inferida.

No extremo NE da área de estudo identificou-se um eixo de uma anomalia magnética de grande amplitude e comprimento, centrado em uma anomalia gravimétrica positiva. Essa anomalia possui direção $\mathrm{N} 60^{\circ}$ E e foi denominada por Rosa $(2007,2009)$ 
como Anomalia Rio Grande (ARG). A noroeste desta anomalia, uma sondagem perfurada pela Petrobras encontrou 0 embasamento (gnaisse) a $194 \mathrm{~m}$ de profundidade. A sudeste dessa mesma anomalia, outra sondagem perfurada pela Petrobras encontrou 0 embasamento (gnaisse) a $515 \mathrm{~m}$ de profundidade. Essas sondagens encontram-se a aproximadamente $30 \mathrm{~km}$ de distância (Fig. 2).

Saadi (1993), em seu trabalho sobre neotectônica na Plataforma Sul Americana, identificou um lineamento com orientação NE-SW no Rio Grande do Sul. Esse lineamento estende-se do nordeste da Lagoa dos Patos ao centro da Lagoa Mirim e foi denominado Lineamento Pelotas (BR-41). Saadi et al. (2002) interpretaram esta estrutura como uma falha, com componentes transcorrente e normal, que possuiria algum tipo de atividade durante 0 Quaternário.

A orientação da ARG aproxima-se do segundo padrão de lineamentos magnéticos identificados por Costa \& Caldasso (1994) e da direção das zonas de cisalhamento Arroio Grande, Vila Ayrosa Galvão e Erval (Philipp, 1998). Portanto, esta estrutura deve representar uma zona de fraqueza herdada do Batólito de Pelotas e reativada na abertura da Bacia de Pelotas. A partir dessas evidências interpreta-se que a ARG é controlada por uma falha com continuidade para sudoeste, que possivelmente, é intersectada por outras falhas ou fraturas de diferentes orientações (E-W e/ou NW-SE). A associação de um alto gravimétrico com um eixo magnético permite inferir que a intrusão de rochas, similares às que compõem o Lineamento Jaguarão e a Anomalia Lagoa Mirim, esteja relacionada à falha que controla a ARG.

A integração dos mapas obtidos a partir dos métodos potenciais, com o mapa geológico (CPRM, 2008) e com o modelo digital de elevação do terreno (SRTM/NASA), permitiu a interpretação de três unidades principais (Fig. 7). Nesse mapa foram definidas regiões de altos gravimétricos, regiões de altos gravimétricos associados com eixos magnéticos e regiões de baixos gravimétricos. As regiões de altos gravimétricos foram interpretadas como zonas onde 0 embasamento é formado por rochas do Escudo Uruguaio-Sul-Rio-Grandense cuja densidade é mais elevada do que a média para a região. Observando-se 0 mapa geológico, verifica-se que na porção noroeste da área de estudo existe uma correlação destes altos com 0 Granito Capão do Leão (Fig. 7).

Os altos gravimétricos associados com eixos magnéticos foram interpretados como zonas com importante presença do magmatismo mesozóico. Esta interpretação não significa que, ao longo de toda a unidade definida, o embasamento seja completamente formado por estas litologias. 0 que se deduz é que as mesmas estejam presentes na forma de diques, sills e possivelmente, derrames de forma a causar um "excesso de massa".

Finalmente, as regiões de baixos gravimétricos foram interpretadas como zonas de embasamento constituído por rochas do Escudo Uruguaio-Sul-Rio-Grandense. Esse embasamento é dominantemente formado pelo Complexo Granito Gnáissico Pinheiro Machado, cuja correlação com o mapa geológico é excelente (Fig. 7).

Observa-se que, muitas destas regiões de baixos gravimétricos, estão associadas a eixos magnéticos. Essa constatação indica a presença de diques relacionados ao magmatismo mesozóico, porém de forma menos expressiva que nas regiões de altos. Em algumas dessas regiões, pode-se inferir que 0 baixo observado seja gerado por uma maior profundidade do embasamento. Porém este fato não pode ser extrapolado para toda a área de estudo, já que sondagens indicando diferentes profundidades do embasamento cristalino (147, 194 e 515 m), junto a baixos gravimétricos, não caracterizam tal interpretação. Para definir essas regiões seria necessária a realização de modelagens considerando as densidades, susceptibilidades magnéticas, volumes e profundidades das diferentes unidades.

A síntese das anomalias descritas e das interpretações realizadas pode ser verificada na Figura 7 e na Tabela 1.

\section{Escala de Detalhe}

No mapa da anomalia Bouguer da área de detalhe, os valores mais elevados ocorrem nas porções sul e oeste, enquanto os valores mais baixos são encontrados na porção nordeste (Fig. 4). Uma interrupção dos altos valores encontrados a oeste foi observada junto ao Banhado do Taim. 0 baixo que se estende e aprofunda-se para leste e nordeste foi denominado Anomalia Taim (AT) (Rosa, 2007 e 2009).

A filtragem do campo regional resultou em um mapa mais heterogêneo, porém a interrupção dos altos gravimétricos presentes na região oeste permanece (Fig. 6). A AT, que no mapa da anomalia Bouguer possuía continuidade para nordeste, é segmentada no mapa residual. Esta segmentação correlaciona-se com um eixo observado no mapa da anomalia magnética residual. Na porção sul da área, verifica-se uma diminuição dos valores após a filtragem do campo regional.

No mapa do campo magnético total observa-se um padrão a sul, com domínio de valores elevados, e um padrão a norte com valores mais baixos (Fig. 4). Após a filtragem, destacam-se os eixos magnéticos E-W que compõem a feição estrutural Lineamento Jaguarão, já descrita na Escala Regional (Fig. 6). A falta de continuidade de alguns destes lineamentos deve-se a falta de 

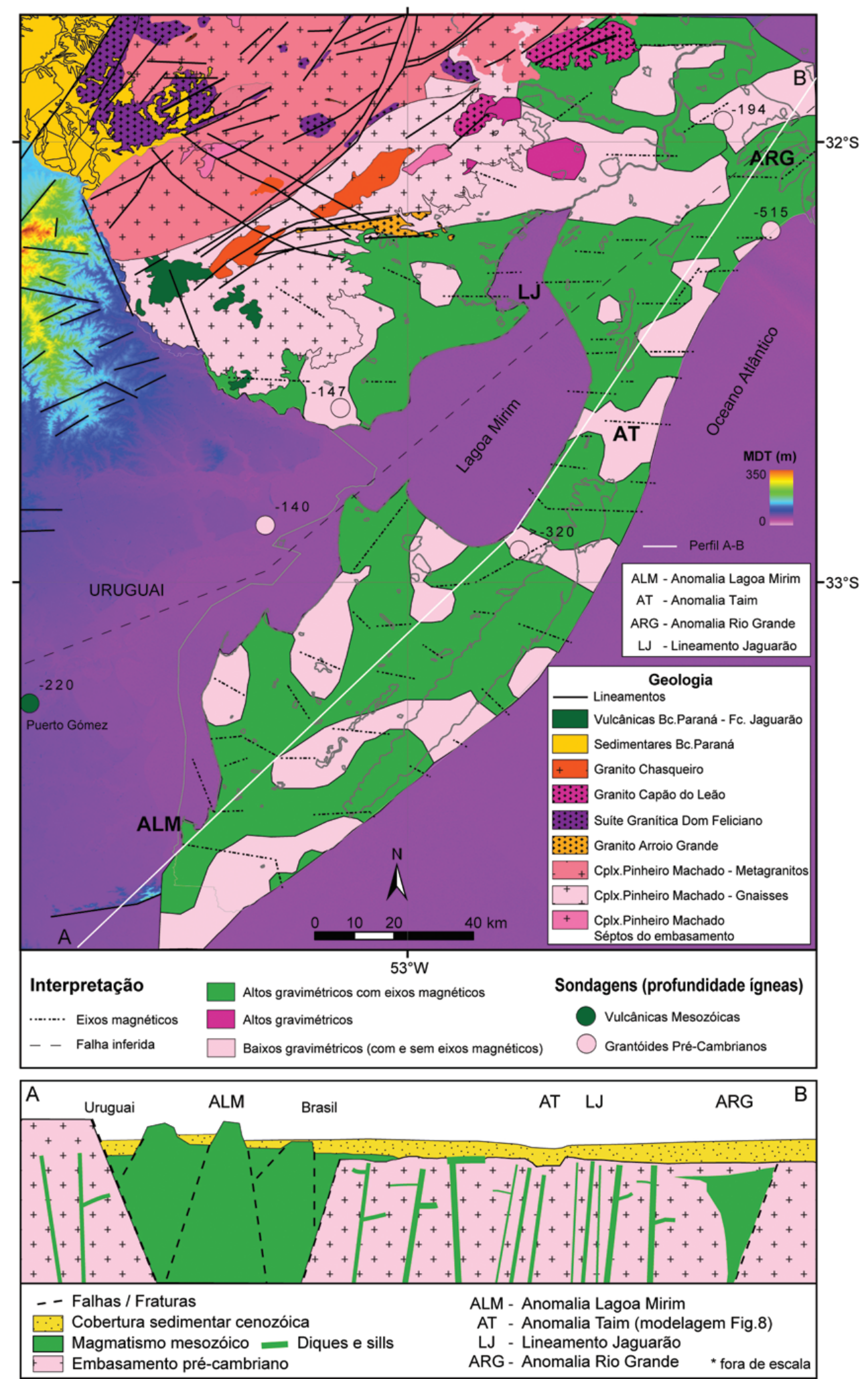

Figura 7 - Interpretações dos mapas residuais (Fig. 5) sobrepostas ao mapa geológico do Escudo Sul-Rio-Grandense (modificado de CPRM, 2008) e ao modelo digital de elevação do terreno (SRTM/NASA). Um perfil esquemático paralelo a linha de costa (SW-NE) ilustra as interpretações obtidas a partir da integração das anomalias identificadas, dados de sondagens e trabalhos anteriores. 
Tabela 1 - Síntese das principais anomalias definidas, destacando sua expressão gravimétrica, magnetométrica e os trabalhos relacionados.

\begin{tabular}{|c|c|c|c|c|}
\hline Anomalia & Gravimetria & Magnetometria & Interpretações & $\begin{array}{l}\text { Trabalhos } \\
\text { relacionados }\end{array}$ \\
\hline $\begin{array}{l}\text { Anomalia } \\
\text { Lagoa Mirim } \\
\text { (ALM) }\end{array}$ & $\begin{array}{l}\text { Alto com } \\
\text { orientação e } \\
\text { ramificações } \\
\text { para NE-SW }\end{array}$ & $\begin{array}{l}\text { Lineamentos } \\
\text { magnéticos } \\
\text { E-W a NW-SE }\end{array}$ & $\begin{array}{l}\text { Zona de ascenção mantélica- } \\
\text { proto dorsal oceânica } \\
\text { relacionada aos momentos } \\
\text { iniciais de abertura do Atlântico } \\
\text { Sul (?). Fraturas preenchidas } \\
\text { pelo magmatismo mesozóico. }\end{array}$ & $\begin{array}{l}\text { Hales (1973); } \\
\text { Reitmayr (1989, } \\
\text { 2001); Rossello } \\
\text { et al. (1999); } \\
\text { Veroslavsky et al. } \\
\quad(2007)\end{array}$ \\
\hline $\begin{array}{l}\text { Lineamento } \\
\text { Jaguarão } \\
(\mathrm{LJ})\end{array}$ & $\begin{array}{l}\text { Altos com } \\
\text { orientação } \\
\text { E-W }\end{array}$ & $\begin{array}{l}\text { Lineamentos } \\
\text { magnéticos } \\
\text { E-W }\end{array}$ & $\begin{array}{c}\text { Diques encaixados } \\
\text { em fraturas. }\end{array}$ & $\begin{array}{c}\text { Prakla (1969); } \\
\text { Costa \& Ramgrab } \\
(1989)\end{array}$ \\
\hline $\begin{array}{l}\text { Anomalia } \\
\text { Rio Grande } \\
\text { (ARG) }\end{array}$ & $\begin{array}{l}\text { Alto circular } \\
\text { que se estende } \\
\text { para WSW } \\
\text { junto ao LJ }\end{array}$ & $\begin{array}{c}\text { Eixo NE-SW } \\
\text { centrado no } \\
\text { alto gravimétrico }\end{array}$ & $\begin{array}{l}\text { Intrusão relacionada ao } \\
\text { magmatismo mesozóico, } \\
\text { controlada por uma falha. }\end{array}$ & $\begin{array}{l}\text { Saadi (1993); } \\
\text { Saadi et al. } \\
(2002) ; \text { Rosa } \\
(2007,2009)\end{array}$ \\
\hline $\begin{array}{l}\text { Anomalia } \\
\text { Taim } \\
\text { (AT) }\end{array}$ & $\begin{array}{l}\text { Baixo com } \\
\text { orientação } \\
\text { E-W com } \\
\text { continuidade } \\
\text { para NNE }\end{array}$ & $\begin{array}{c}\text { Lineamentos } \\
\text { magnéticos } \\
\text { E-W que } \\
\text { segmentam o } \\
\text { baixo gravimétrico }\end{array}$ & $\begin{array}{l}\text { Calha no embasamento } \\
\text { preenchida por sedimentos, } \\
\text { controlada por fraturas } \\
\text { associadas ao LJ. }\end{array}$ & $\begin{array}{l}\text { Rosa (2007, } \\
\text { 2009) }\end{array}$ \\
\hline
\end{tabular}

estações no centro da região, ocupado pela porção norte da Lagoa Mangueira e pelo Banhado do Taim (Fig. 2). Dessa forma, a continuidade destes lineamentos pode ser admitida a partir da comparação com os lineamentos verificados no trabalho de Costa \& Ramgrab (1989), que utilizaram dados aeromagnéticos.

A interpretação da AT através dos mapas gravimétricos, assim como qualquer interpretação baseada em métodos potenciais, não é unívoca. Uma primeira interpretação possível é a existência de uma calha no embasamento, possibilitando a deposição de uma espessura maior de sedimentos e por conseqüência uma diminuição no valor da anomalia Bouguer. Uma segunda interpretação seria a ocorrência de rochas mais densas (p.ex. intrusões básicas) entre as quais uma litologia menos densa (p.ex. granitóides) geraria a variação observada. Uma terceira possibilidade seria a combinação das duas anteriores, com rochas mais densas delimitando a ocorrência de rochas menos densas e mais profundas.

Para elucidar qual das interpretações é a mais provável, procedeu-se a integração entre os mapas gerados na área de detalhe (Figs. 4 e 6). Na comparação realizada, observa-se que as anomalias magnéticas que caracterizam 0 Lineamento Jaguarão, ocorrem tanto sobre altos quanto baixos gravimétricos. A existência de uma heterogeneidade na composição do embasamento é evidenciada pela continuidade do Lineamento Jaguarão para leste da Lagoa Mirim. Como já descrito anteriormente, a oeste dessa lagoa afloram rochas da Formação Serra Geral, bem como granitóides do Escudo Uruguaio-Sul-Rio-Grandense. A presença de gnaisses em sondagens perfuradas pela Petrobras, próximas aos municípios de Rio Grande e de Pelotas, também demonstra a presença de litologias deste escudo. Dessa forma, sugere-se a associação entre uma depressão no relevo do embasamento granítico com fraturas de orientação $\mathrm{E}-\mathrm{W}$, preenchidas por rochas básicas.

A modelagem realizada em um perfil, cuja posição é destacada na Figura 6, revela uma excelente correlação entre os valores observados e calculados para a solução proposta (Fig. 8). 0 contraste de densidade considerado para as unidades baseia-se em medidas realizadas no trabalho de Costa (1997). Para diabásios foram obtidos valores médios de densidade de $2,923 \mathrm{~g} / \mathrm{cm}^{3}$. Para as rochas do embasamento granito-gnáissico, correspondentes aos que afloram na região oeste da área de estudo, foi obtida uma média de 2,674 g/ $/ \mathrm{cm}^{3}$. 0 contraste resultante é de $0,249 \mathrm{~g} / \mathrm{cm}^{3}$. Para os sedimentos da Bacia de Pelotas, foi considerada uma densidade de $2,20 \mathrm{~g} / \mathrm{cm}^{3}$, mesmo valor utilizado por Reitmayr (2001) na modelagem da Anomalia Lagoa Mirim. Comparações com trabalhos realizados na Bacia de Taubaté (Fernandes \& Chang, 2001) e na Bacia de Santos (Mio et al., 2005), revelam que a densidade considerada é compatível com os depósitos da Bacia 


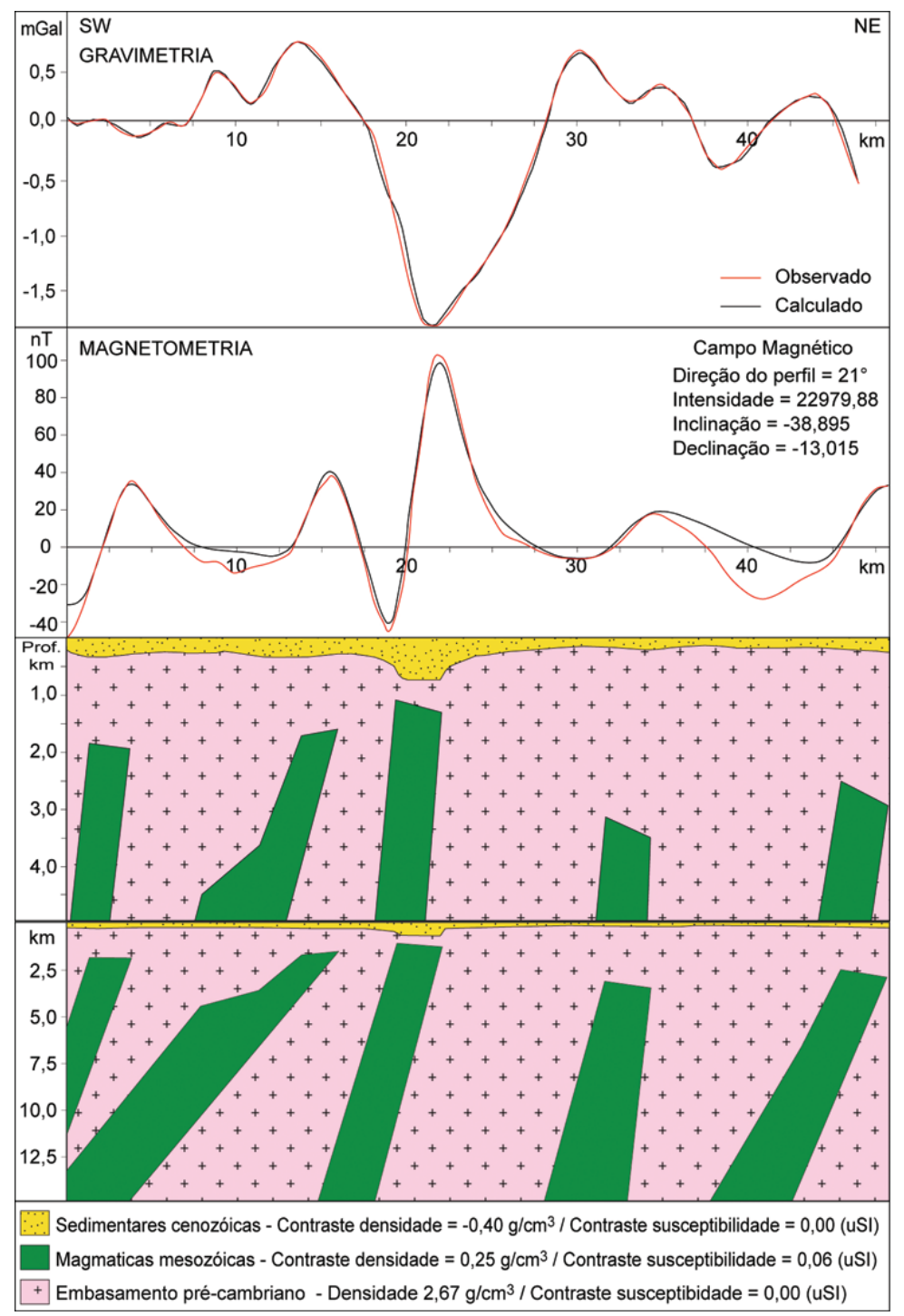

Figura 8 - Modelagem gravimétrica e magnetométrica 2.5D integrada de um perfil gerado na região do Banhado do Taim. Para aumentar o exagero vertical e destacar a morfologia do topo do embasamento da bacia são apresentadas duas seções geológicas. A primeira com $5 \mathrm{~km}$ de profundidade, e a segunda, com o modelo completo obtido até $15 \mathrm{~km}$ de profundidade. A grande continuidade lateral das intrusões magmáticas mesozóicas provavelmente representa a soma da resposta de corpos menos extensos.

de Pelotas na área de estudo, caracterizados por um baixíssimo grau de litificação (Ghignone, 1960).

As susceptibilidades magnéticas utilizadas para os corpos magmáticos mesozóicos baseiam-se nos valores empregados por Costa \& Ramgrab (1989), Costa (1997) e Reitmayr (2001). Determinou-se um contraste de 0,06 (USI) entre estes corpos magmáticos e as unidades do Escudo Sul-Rio-Grandense e da Bacia de Pelotas.

Como resultado verifica-se a presença de rochas magnéticas, associadas ao magmatismo mesozóico, em uma posição imediatamente abaixo a uma das bordas da anomalia gravimétrica ne- gativa. Essa verificação indica uma "falta de massa", mesmo com a presença de uma intrusão de densidade elevada. Esse déficit é explicado como uma maior espessura de sedimentos depositados em uma calha do embasamento. A espessura máxima de sedimentos obtida com a modelagem foi de 740 m e a mínima de $150 \mathrm{~m}$. 0 topo das rochas magmáticas está posicionado entre 1.090 e $3.150 \mathrm{~m}$ de profundidade. Os corpos magmáticos possuem extensões horizontais entre 2,5 e $5 \mathrm{~km}$. Essa grande continuidade provavelmente representa a soma da resposta de corpos menos extensos, os quais poderiam ser individualizados somente através de mapas residuais com freqüências mais altas. Como 
dito anteriormente, esses mapas não foram gerados devido à irregularidade da malha de dados.

Na área de detalhe estão presentes sistemas deposicionais do tipo Laguna-Barreira de idade pleistocênica (II e III) e holocênica (IV) (Villwock et al., 1986). Na região do Banhado do Taim, as barreiras pleistocênicas (II e III) encontram-se segmentadas (Fig. 2). Villwock \& Tomazelli (1995) atribuíram essa segmentação a uma zona de drenagem ativa durante a última regressão, em torno de 17,5 ka (Corrêa, 1995). Posteriormente, o nível do mar se elevou, ultrapassando o nível atual há cerca de 7,7-6,9 ka atrás (Martin et al., 2003; Angulo et al., 2006). Nesta fase, a área deve ter se comportado como um estuário (Barboza et al., 2007). A partir de então, cordões litorâneos regressivos progradaram, fechando a conexão entre as lagoas Mirim e Mangueira com 0 Oceano Atlântico.

A interpretação de um baixo gravimétrico em resposta a uma calha do embasamento, na mesma posição da segmentação das barreiras pleistocênicas, sugere um controle da herança geológica. Esse controle seria responsável pela recorrente instalação de canais fluviais durante os eventos regressivos. Portanto, esta região pode ser considerada como uma área preferencial na transferência de sedimentos para as porções mais profundas da bacia.

Porém, esta constatação remete a outra questão: como uma feição em grande profundidade poderia controlar os sistemas deposicionais recentes? Esse controle poderia estar associado a uma movimentação relativamente recente do embasamento, a um recalque diferencial condicionado pela natureza dos sedimentos depositados na área, ou ainda à geração de perturbações causadas por desequilíbrios hidráulicos. Uma observação realizada na região, através do modelo digital de elevação do terreno e em perfis realizados com DGPS, refere-se a um suave mergulho das barreiras pleistocênicas, de SW para NE, em direção ao Banhado do Taim. Tal observação pode indicar a ocorrência de subsidência diferencial, gerando o mergulho das barreiras em direção ao Banhado do Taim.

\section{CONCLUSÕES}

A interpretação integrada dos métodos potenciais em um SIG permitiu caracterizar 0 embasamento da Bacia de Pelotas na área de estudo. Devido à impossibilidade da realização de medidas em amplas regiões (lagoas, banhados) não foi possível se obter um mapa do embasamento, mas sim constatar as principais variações litológicas e estruturais no substrato da Bacia de Pelotas.

Verificou-se uma complexa estruturação com a presença de blocos escalonados, falhas e fraturas, além de uma heterogeneidade composicional. Essa variação está relacionada com a evolução do Escudo Uruguaio-Sul-Rio-Grandense e com a abertura do Oceano Atlântico Sul, refletindo uma série de feições geradas e/ou herdadas e reativadas durante a separação dos continentes sul-americano e africano.

Nas regiões em que se constatou uma correlação de anomalias gravimétricas positivas com eixos magnéticos, interpretouse a ocorrência do magmatismo relacionado a esta separação. Uma dessas correlações ocorre na região sul, junto à Anomalia Lagoa Mirim, que registra os momentos iniciais da geração de crosta oceânica durante a abertura da Bacia de Pelotas. Apesar das diversas interpretações referentes a essa anomalia e ao seu potencial econômico, sua ligação com os momentos iniciais da Bacia de Pelotas é um consenso. A Anomalia Lagoa Mirim reflete a interação dos processos tectônicos com o magmatismo, que mesmo após seu clímax de atividade continuou influenciando os processos de subsidência, devido à sua elevada densidade.

A tectônica do rifteamento também foi verificada em outras regiões como na Anomalia Rio Grande, que evidencia a presença de falhas e blocos escalonados no embasamento. Com o auxílio de duas sondagens verificou-se a provável intersecção de uma falha nordeste, com outras falhas ou fraturas (E-W e/ou NW-SE). Esta zona de fraqueza estrutural contribuiu para a intrusão de rochas densas e magnéticas (p.ex. diabásio). Tal constatação confirma a interpretação de Saadi (1993), da existência de uma falha com orientação NE-SW na região.

A continuidade para leste das anomalias magnéticas definidas como Lineamento Jaguarão por Costa \& Ramgrab (1989) foi constatada. A existência de anomalias similares a sul também pôde ser verificada. Sugere-se a continuidade dessas anomalias para oeste, no Uruguai, e para leste, em direção à plataforma continental.

Finalmente, foi constatada a presença de uma anomalia gravimétrica negativa junto ao Banhado do Taim, interpretada como uma calha no embasamento. Essa feição corresponde a uma zona de transferência de sedimentos para as regiões mais distais da Bacia de Pelotas, ativa durante períodos de queda do nível do mar. Uma das possíveis zonas de deposição destes sedimentos é o Cone do Rio Grande, um prisma sedimentar com mais de $10.000 \mathrm{~m}$ de espessura (Martins et al., 1972).

Essa observação permite inferir que na região do Taim exista uma sobreposição de depósitos fluviais em conseqüência da recorrente instalação de vales incisos. Esses depósitos estariam intercalados com a sedimentação gerada nos momentos de elevação do nível do mar (Tomazelli et al., 2008). Portanto, 0 registro estratigráfico dessa região foi condicionado pela existência de uma feição no embasamento sugerindo 0 controle da 
herança geológica. Esse controle pode estar relacionado com a reativação de falhas e com a ocorrência de subsidência diferencial devido à heterogeneidade das litologias presentes no embasamento. Estudos futuros com a aquisição de novos dados em regiões onde não foram realizadas medidas (lagoas, banhados) e a integração com outros métodos poderão melhorar e permitirão testar as interpretações realizadas.

\section{AGRADECIMENTOS}

Agradecemos ao Centro de Estudos de Geologia Costeira e Oceânica e aos departamentos de Geodésia e Geologia do Instituto de Geociências da Universidade Federal do Rio Grande do Sul pela infra-estrutura e equipamentos disponibilizados. Ao Projeto "Implantação, desenvolvimento e preenchimento de vales incisos na porção sul da Planície Costeira do Rio Grande do Sul" (CECO/UFRGS/PETROBRAS), agradecemos 0 apoio financeiro para a realização dos trabalhos de campo. Agradecemos à Agência Nacional do Petróleo, Gás Natural e Biocombustíveis (ANP), através do Programa de Recursos Humanos (PRH-12), pela bolsa de mestrado concedida à M.L.C.C. Rosa. Ao professor Dr. Sérgio Florêncio de Souza agradecemos pela disponibilização do programa Anomalia para a correção dos dados gravimétricos e ao Dr. G.R.J Cooper da Universidade de Witwatersrand, pela disponibilização dos programas Grav2dc e Mag2dc para a realização da modelagem. Agradecemos também as sugestões dos professores Dr. Sérgio Rebello Dillenburg, Dr. Farid Chemale Jr, Dr. Francisco José Fonseca Ferreira e dos revisores, as quais contribuíram sobremaneira com 0 trabalho realizado.

\section{REFERÊNCIAS}

ALMEIDA FFM, HASUI Y, NEVES BBB \& FUCK RA. 1981. Brazilian Structural Provinces: an introduction. Earth Science Review, 17: 1-29.

ALVES EC. 1981. Estruturas da Margem Continental Sul Brasileira e das áreas oceânicas e continentais adjacentes. In: ASMUS HE (Ed.). Estruturas e tectonismo da Margem Continental Brasileira e suas implicações nos processos sedimentares e na avaliação do potencial de recursos minerais. Rio de Janeiro, Petrobras/Cenpes/Dintep. Série Remac 9, p. 187-269.

ANGULO RJ, LESSA GC \& SOUZA MC. 2006. A critical review of Midto Late-Holocene sea-level fluctuations on the eastern Brazilian coastline. Quaternary Science Reviews, 25: 486-506.

ASMUS HE \& PAIM PSG. 1986. Condicionamento geológico na evolução da Planície Costeira Sul-riograndense. In: Congresso Brasileiro de Geologia, 34: 1986, Goiânia. Anais... Goiânia: SBG, 1: 461-471.
ASMUS HE \& PORTO R. 1972. Classificação das bacias sedimentares brasileiras segundo a tectônica de placas. In: Congresso Brasileiro de Geologia, 26: 1972, Belém. Anais... Belém: SBG, 2: 67-90.

AYUP-ZOUAIN RN, FERREIRA HPL, BARBOZA EG \& TOMAZELLI LJ. 2003. Evidência morfológica de um paleocanal holocênico da Laguna Mirim nas adjacências do Banhado Taim. In: Congresso da Associação Brasileira de Estudos do Quaternário, 9: 2003, Recife. Livro de Resumos... Recife: ABEQUA. p. 86.

BABINSKI M, CHEMALE JR F, VAN SCHMUS WR, HARTMANN LA \& SILVA LC. 1997. U-Pb and Sm-Nd geochronology of the neoproterozoic granitic-gneissic Dom Feliciano Belt, southern Brazil. Journal of South American Earth Sciences, 10(3): 263-274.

BARBOZA EG, AYUP-ZOUAIN RN, TOMAZELLI LJ \& ROSA MLCC. 2007. Significado estratigráfico e paleogeográfico da paleoembocadura do Taim. In: Congresso da Associação Brasileira de Estudos do Quaternário, 11: 2007, Belém. Anais... Belém. 1 CD-ROM.

BOSSI J \& FERRANDO L. 2001. Carta geológica del Uruguay. Universidad de la República - Facultad de Agronomía. Escala 1:500.000. 1 CD-ROM.

BOSSI J \& UMPIERRE M. 1975. Magmatismo mesozoico del Uruguay y Río Grande del Sur: sus recursos minerales asociados y potenciales. In: Congreso Iberoamericano de Geología Económica, 2: 1975, Buenos Aires. Actas... Buenos Aires: p. 119-142.

BOSSI J, FERRANDO L, MONTAÑA J, CAMPAL N, MORALES H, GANCIO F, SCHIPILOV A, PIÑEYRO D \& SPRECHMANN P. 1998. Carta geológica del Uruguay. Cátedra de Geología y Facultad de Agronomía. Escala 1:500.000. 1 CD-ROM.

CAORSI J \& GOÑI J. 1958. Geología uruguaya. Boletín del Instituto Geológico del Uruguay, Montevideo. Uruguay, 37: 1-73.

CHEMALE JR F, HARTMANN LA \& SILVA LC. 1995. Stratigraphy and tectonism of the brasiliano cycle in southern Brazil. Communications of the Geological Survey of Namibia, 10: 151-166.

COBBOLD PR, SZATMARI P, LIMA C \& ROSSELLO EA. 1996. Cenozoic deformation across South America: continent-wide data and analogue models. In: International Symposium on Andean Geodynamics, 3: 1996, Saint Maló, França. Orstom-Geosciences Rennes... p. 21-24.

CORREA ICS. 1995. Les variations du niveau de la mer durant les derniers 17.500 ans BP: l'exemple de la plate-forme continentale du Rio Grande do Sul-Brésil. Marine Geology, 130: 163-178.

COSTA AFU. 1997. Teste e modelagem geofísica da estruturação das associações litotectônicas pré-cambianas no Escudo Sul-Rio-Grandense. Porto Alegre. 2v. 291 p. Tese de Doutorado em Geociências, Instituto de Geociências, Universidade Federal do Rio Grande do Sul.

COSTA AFU \& CALDASSO ALS. 1994. Padrões do campo magnético aplicados a geologia estrutural na região de Pinheiro Machado, RS. 
In: Congresso Brasileiro de Geologia, 38: 1994, Balneário Camboriú: SBG, p. 31-32.

COSTA AFU \& RAMGRAB GE. 1989. Lineamento Jaguarão - caracterização aeromagnética. Revista Brasileira de Geofísica, 7(1): 41-45.

CPRM - SERVIÇO GEOLÓGICO DO BRASIL. 2008. Geologia e Recursos Minerais do Estado do Rio Grande do Sul. Programa de Geologia do Brasil. Integração, Atualização e Difusão de Dados de Geologia do Brasil. Mapas Geológicos Estaduais em Sistema de Informações Geográficas SIG. Escala 1:750.000. DVD ROM.

FERNANDES LAD, MENEGAT R, COSTA AFU, KOESTER E, PORCHER CC, TOMMASI A, KRAEMER G, RAMGRAB GE \& CAMOZATTO E. 1995. Evolução tectônica do Cinturão Dom Feliciano no Escudo Sul-RioGrandense: Parte I - uma contribuição a partir do registro geológico. Revista Brasileira de Geociências, 25(4): 351-374.

FERNANDES FL \& CHANG HK. 2001. Modelagem gravimétrica da Bacia de Taubaté - Vale do Rio Paraíba do Sul, leste do Estado de São Paulo. Revista Brasileira de Geofísica, 19(2): 131-144.

FONSECA VP. 2006. Estudos morfotectônicos aplicados à Planície Costeira do Rio Grande do Sul e adjacências. Porto Alegre. 307 p. Tese de Doutorado em Geociências, Instituto de Geociências, Universidade Federal do Rio Grande do Sul.

FRAGOSO-CÉSAR ARS, WERNICK E \& SOLIANI JR E. 1982. Associações petrotectônicas do Cinturão Dom Feliciano (SE da Plataforma Sulamericana). In: Congresso Brasileiro de Geologia, 32: 1982, Salvador. Anais... Salvador: SBG, 1: 1-12.

FRAGOSO-CÉSAR ARS, FIGUEIREDO MCH, SOLIANI JR E \& FACCINI UF. 1986. 0 Batólito de Pelotas (Proterozóico Superior/Eo-Paleozóico) no Escudo do Rio Grande do Sul. In: Congresso Brasileiro de Geologia, 34: 1986, Goiânia. Anais... Goiânia: SBG, 3: 1322-1343.

GAMBOA LAP \& RABINOWITZ PD. 1981. The Rio Grande Fracture Zone in the western South Atlantic and its tectonic implications. Earth and Planetary Science Letters, Amsterdam, 52: 410-418.

GHIGNONE JI. 1960. Reconhecimento gravi-magnético na Bacia de PeIotas. Boletim Técnico Petrobras, 3(2): 73-79.

GÓMEZ RCG \& MASQUELIN AHC. 1996. Petrología y geoquímica de las rocas volcánicas cretácicas del Uruguay. In: XIII Congreso Geológico Argentino y III Congreso de Exploración de Hidrocarburos, 1996, Buenos Aires, Argentina. Actas... Buenos Aires, 3: 635-652.

HALES FW. 1973. A anomalia gravitacional Chuí, Rio Grande do Sul. DNPM, $1^{\circ}$ Distrito Extremo Sul. Relatório Interno, n. 24.

IMBRIE J, HAYS JD, MARTINSON DG, MCINTYRE A, MIX AC, MORLEY JJ, PISIAS NG, PRELL WL \& SHACKLETON NJ. 1984. The orbital theory of Pleistocene climate: support from a revised chronology of the marine $\delta 0^{18}$ record. In: BERGER A, IMBRIE J, HAYS J, KUKLA G \& SALTZMAN B (Eds.). Milankovitch and Climate, Part I, Reidel, p. 269-305.
INTROCASO A \& HUERTA E. 1982. Interpretación del exceso de gravedad en Uruguay. In: Congreso Latinoamericano de Geología, 5., 1982, Buenos Aires. Actas... Buenos Aires, 4: 87-104.

MARTIN L, DOMINGUEZ JML \& BITTENCOURT ACSP. 2003. Fluctuating Holocene sea levels in Eastern and Southeastern Brazil: evidence from multiple fossil and geometric indicators. Journal of Coastal Research, 19: 101-124.

MARTINS LR, URIEN CM \& BUTLER LW. 1972. Províncias fisiográficas e sedimentos da Margem Continental Atlântica da América do Sul. In: Congresso Brasileiro de Geologia, 26: 1972, Belém. Anais... Belém: SBG, 105-114.

MILANI AJ. 2000. Geodinâmica fanerozóica do Gondwana sul-ocidental e a evolução geológica da Bacia do Paraná. In: HOLZ M \& DE ROS LF (Eds.). Geologia do Rio Grande do Sul. Porto Alegre: CIGO. p. 275-302.

MIO E, CHANG HK \& CORRÊA FS. 2005. Integração de métodos geofísicos na modelagem crustal da Bacia de Santos. Revista Brasileira de Geofísica, 23(3): 275-284.

PHILIPP RP. 1998. A evolução geológica e tectônica do Batólito de Pelotas no Rio Grande do Sul. São Paulo, 255 p. Tese de Doutorado. Instituto de Geociências, Universidade de São Paulo.

PHILIPP RP \& MACHADO R. 2001. Estratigrafia e significado tectônico das suítes graníticas do Batólito de Pelotas no RS. Revista Brasileira de Geociências, 31(3): 257-266.

PHILIPP RP, MACHADO R \& CHEMALE JR F. 2003. Reavaliação e novos dados geocronológicos (Ar/Ar, Rb/Sr e Sm/Nd) do Batólito de Pelotas no Rio Grande do Sul: implicações petrogenéticas e idade de reativação das zonas de cisalhamento. Revista do Instituto de Geociências da Universidade de São Paulo, 3: 71-84.

PRAKLA. 1969. Aeromagnetometrical surveys Continental Platform interpretation. PETROBRAS-DEXPRO-DIVEX. Relatório Interno, n. 3311.

REITMAYR G. 1989. La anomalía gravimétrica en el extremo sur de la Laguna Merín (Uruguay/Brasil). In: Congresso da Sociedade Brasileira de Geofísica, 1: 1989. Rio de Janeiro. Anais... Rio de Janeiro: SBGf, p. 544-549.

REITMAYR G. 2001. Una espectacular peculiaridad uruguaya: Ia anomalía gravimétrica de la Laguna Merín. In: Congreso Latinoamericano de Geología, 11: 2001, Montevideo. Actas... Montevideo. 1 CD-ROM.

ROSA MLCC. 2007. Caracterização geofísica do embasamento da região sul da Planície Costeira do Rio Grande do Sul. Porto Alegre. 93 p. Trabalho de Conclusão do Curso de Geologia. Instituto de Geociências. Universidade Federal do Rio Grande do Sul.

ROSA MLCC. 2009. Análise gravimétrica e magnetométrica da região sul da Província Costeira do Rio Grande do Sul, setor sudoeste da Bacia de Pelotas. Porto Alegre. 79 p. Dissertação de Mestrado em Geociências, Instituto de Geociências, Universidade Federal do Rio Grande do Sul. 
Disponível em: <http://hdl.handle.net/10183/15952>. Acesso em: 31 maio 2009.

ROSA MLCC, BARBOZA EG, TOMAZELLI LJ, AYUP-ZOUAIN RN \& DILLENBURG SR. 2007. Aplicação de ferramentas de visualização tridimensional na modelagem geomorfológica da região sul da Província Costeira do Rio Grande do Sul. Gravel, 5: 1-10.

ROSSELLO EA, SANTA ANA H \& VEROSLAVSKY G. 1999. El lineamiento Santa Lucía-Aiguá-Merín (Uruguay): un rifting transtensivo mesozoico abortado durante la apertura atlántica? In: Simpósio sobre o Cretáceo do Brasil, 5: 1999, Campos de Rio Claro, São Paulo. Boletim de Resumos... p. 443-448.

ROSSELLO EA, VEROSLAVSKY G, MASQUELIN H \& SANTA ANA H. 2007. El corredor juro-cretácico Santa Lucía-Aiguá-Merín (Uruguay): cinemática transcurrente dextral y controles preexistentes. Revista de la Asociación Geológica Argentina, 62(1): 92-104.

SAADI A. 1993. Neotectônica da Plataforma Brasileira - esboço e interpretações preliminares. Geonomos, 1: 1-15.

SAADI A, MACHETTE MN, HALLER KM, DART RL, BRADLEY LA \& SOUZA AMPD. 2002. Map and database of quaternary faults and lineaments in Brazil. USGS/UFMG. International Lithosphere Program, Task Group II-2, Major Active Faults of the World.

SHACKLETON NJ \& OPDYKE ND. 1973. Oxygen isotope and palaeomagnetic stratigraphy of Equatorial Pacific Core V28-238: oxygen isotope temperatures and ice volumes on a $10^{5}$ year and $10^{6}$ year scale. Quaternary Research, 3: 39-55.

SOLIANI JR E. 1986. Os dados geocronológicos do Escudo Sul-Riograndense e suas implicações de ordem geotectônica. São Paulo. 239 p. Tese de Doutorado em Geociências, Universidade de São Paulo.

TALWANI M, WORZEL JM \& LANDISMAN M. 1959. Rapid gravity computations for two-dimensional bodies with application to the Mendocino
Submarine Fracture Zone. Journal of Geophysical Research, 64: 49-59.

TOMAZELLI LJ, BARBOZA EG, DILLENBURG SR, ROSA MLCC, CARON F \& LIMA LG. 2008. Implantação, preenchimento e desenvolvimento de vales incisos na porção sul da Planície Costeira do Rio Grande do Sul. Projeto PETROBRAS. Relatório Interno.

TURNER SP, REGELOUS M, KELLEY S, HAWKESWORTH CJ \& MANTOVANI MSM. 1994. Magmatism and continental break-up in the South Atlantic: high precision Ar-Ar geochronology. Earth and Planetary Science Letters, 121: 333-348.

URIEN CM \& MARTINS LR. 1978. Structural and physiographic map of eastern South America and western South Africa. CECO/UFRGS. Série Mapas, 03. Porto Alegre, Brasil.

VEROSLAVSKY G, ROSSELLO EA, MUZIO R \& SANTA ANA H. 2007. Tectónica y magmatismo de la Cuenca Laguna Merín: relictos de una proto dorsal oceánica jurocretácica. In: Congreso Uruguayo de Geología, 5: 2007, Montevideo. Resúmenes... Montevideo. 1 CD-ROM.

VIEIRA JR N \& ROISENBERG A. 1985. Formação Jaguarão - uma nova unidade vulcânica mesozóica no RS. In: Simpósio Sul-Brasileiro de Geologia, 2: 1985, Florianópolis. Anais... Florianópolis: SBG, p. 507.

VILLWOCK JA. 1984. Geology of the Coastal Province of Rio Grande do Sul, Southern Brazil. A synthesis. Pesquisas, 16: 5-49.

VILLWOCK JA \& TOMAZELLI LJ. 1995. Geologia Costeira do Rio Grande do Sul. Notas Técnicas. CECO, Instituto de Geociências, UFRGS, Porto Alegre, n.8, 45 p.

VILLWOCK JA, TOMAZELLI LJ, LOSS EL, DEHNHARDT EA, HORN F० NO, BACHI FA \& DENHARDT BA. 1986. Geology of the Rio Grande do Sul Coastal Province. In: RABASSA J (Ed.). Quaternary of South America and Antarctic Peninsula. Rotterdam, A.A. Balkema, 4: 79-97.

\section{NOTAS SOBRE OS AUTORES}

Maria Luiza Correa da Camara Rosa. Geóloga (2007) e Mestre em Geociências (2009) pela Universidade Federal do Rio Grande do Sul (UFRGS). Em 2009, iniciou seu projeto de Doutorado junto ao Programa de Pós-Graduação em Geociências da UFRGS, na área de concentração de Estratigrafia. Atualmente é professora substituta no Departamento de Geodésia da UFRGS e trabalha em projetos de pesquisa no Centro de Estudos de Geologia Costeira e Oceânica (CECO) com ênfase em Geofísica, Estratigrafia e Sensoriamento Remoto aplicados à Geologia Costeira.

Luiz José Tomazelli. Possui graduação em Geologia (1973), Mestrado (1977) e Doutorado em Geociências (1990), pela Universidade Federal do Rio Grande do Sul (UFRGS). Professor titular aposentado do Instituto de Geociências da UFRGS, atualmente é pesquisador do Centro de Estudos de Geologia Costeira e Oceânica (CECO), professor e orientador de Mestrado e Doutorado do Programa de Pós-Graduação em Geociências da UFRGS. Atua nas áreas de Geologia Costeira, Marinha e Estratigrafia.

Antonio Flávio Uberti Costa. Geólogo formado em 1974 pela Universidade Federal do Rio Grande do Sul (UFRGS) possui especialização em Geofísica (1977) pela UFPA. Finalizou seu Doutorado no Programa de Pós-Graduação em Geociências da UFRGS em 1997. Trabalhou como geofísico na Petrobras e na CPRM e atualmente é professor de Geofísica do Instituto de Geociências da UFRGS e Diretor da AFC Geofísica.

Eduardo Guimarães Barboza. Geólogo formado em 1996, possui Mestrado (1999) e Doutorado (2005) em Geociências pela Universidade Federal do Rio Grande do Sul (UFRGS). Atualmente é professor adjunto do Instituto de Geociências da UFRGS, pesquisador do Centro de Estudos de Geologia Costeira e Oceânica (CECO) e professor do Programa de Pós-Graduação em Geociências da UFRGS. Atua principalmente nas áreas de Estratigrafia, Geologia Costeira e Sensoriamento Remoto. 